\title{
UM TRABALHO NATURALMENTE FEMININO? Discussões feministas no Cone Sul (1970-1990)
}

\author{
Soraia Carolina de Mello*
}

\section{Resumo}

A relação entre mulheres e trabalho doméstico, ainda que afirmada pelos feminismos e pelos estudos de gênero como culturalmente construída, tem seu principal aporte na ideia de naturalização dessas funções. Nesta pesquisa me propus a escrever uma história da discussão em torno da naturalização do trabalho doméstico nos feminismos de Segunda Onda do Cone Sul, utilizando como fonte as produções impressas desses feminismos, com ênfase em periódicos, mas não somente. É importante destacar que o meu recorte temporal é dado pelas fontes utilizadas e que, através delas, busco estabelecer uma discussão a respeito da problematização do trabalho doméstico nos feminismos de Segunda Onda no Cone Sul, partindo de uma perspectiva historiográfica, inserida nos estudos feministas e de gênero, com o apoio de bibliografia tanto contemporânea aos documentos utilizados quanto atual.

Palavras-chave: Trabalho Doméstico. História do Feminismo. Segunda Onda Feminista. Cone Sul. Imprensa Feminista.

A nível coletivo (sic), a decisão da mulher de não ser dona-de-casa (sic) seria tão revolucionária que destruiria a organização social que agora conhecemos. Para reforçar a situação, para manter as coisas tal como estão e afastar a ameaça de uma revolta, criou-se a doutrina da posição natural da mulher na família como dona-de-casa. (...) A ocupação da dona-de-casa não é natural, mas histórica. No atual estágio da técnica só a maternidade é função naturalmente feminina, mas entre a gestação e o parto e as duzentas mil horas de trabalho doméstico que executa uma dona-de-casa ao longo de sua vida, não há nenhuma correspondência necessária, mas apenas circunstancial. (DURAN, 1983, p. 15. Grifos da autora.)

O fato de o trabalho doméstico ser uma função designada em diferentes sociedades como exclusivamente ou primordialmente feminina não é novidade para ninguém. Não são

\footnotetext{
* Mestre em História Cultural pela Universidade Federal de Santa Catarina. Email: soraiaa.mello@gmail.com.
} 
necessários dados estatísticos ou bibliografia de referência no assunto para saber que esse trabalho, que na maioria das vezes não é reconhecido como trabalho, é “coisa de mulher”. E essa relação entre mulheres e trabalho doméstico, ainda que afirmada pelos feminismos e pelos estudos de gênero como culturalmente construída, tem seu principal aporte na ideia da naturalização dessas funções. A família e a maternidade se mostram como as principais legitimadoras de tal relação, que traz em si o peso de séculos de reafirmação de que "ser mulher” é ter cuidado, reclusão, dedicação, paciência; é se voltar para a esfera privada, é ser esposa e ser mãe.

A naturalização do trabalho doméstico como função feminina se insere em um grupo de ideias a respeito de relações sociais e morais que são comumente identificadas como conservadoras ou tradicionais, e que os feminismos ${ }^{1}$, em especial os de Segunda Onda ${ }^{2}$, relacionavam diretamente ao domínio patriarcal ${ }^{3}$. Pesquisas atuais (ARAÚJO, 2005) indicam que valores tradicionais convivem com novos valores de uma maneira complexa em nossa sociedade, em especial nas famílias; e a grande representação dos valores tradicionais, a questão que parece de alguma forma intocada ou muito pouco tocada pelos "novos tempos", é exatamente a do trabalho doméstico. É ainda mais impressionante observar que as mulheres casadas jovens, em geral, apresentam posições mais conservadoras do que as esposas de meia-idade, equiparando-se às opiniões das esposas de idade avançada (PICANÇO, 2005, pg. 160). Ou seja, a que poderia ser chamada de “nova geração” apresenta posições mais conservadoras que a geração anterior, contrariando expectativas de que o recorte geracional tende a caminhar para a “abertura”, no sentido de que quanto mais jovens as pessoas, menos conservadoras.

A partir do pressuposto de que o trabalho doméstico feminino é largamente presente, que é transversal no que se refere à classe ou a características mais culturais, como religião ou nacionalidade (RIBEIRO, 2005, p. 173-201), e que apresenta relativa estagnação se comparado com outros aspectos da vida privada e de liberdades individuais das mulheres, vale parar para observar a questão. Este trabalho ${ }^{4}$ vem observar, através dos impressos

\footnotetext{
${ }^{1}$ Utilizo “feminismos", no plural, entendendo o movimento como múltiplo e heterogêneo, e não homogêneo, unificado.

${ }^{2}$ Sobre a periodização do feminismo aqui utilizado ver PEDRO, 2006.

${ }^{3}$ A ideia de uma ordem ou sistema patriarcal, que legitimaria e manteria a opressão das mulheres, foi muito corrente nos feminismos de Segunda Onda. Apesar de no Brasil esse conceito ter perdido força, ele ainda é encontrado e, em outros países da América Latina parece ser mais corrente. Exemplos em HENAUT, 2001; e em BEDREGAL, 2007.

${ }^{4}$ Este trabalho é resultado da pesquisa de Mestrado intitulada "Feminismos de Segunda Onda no Cone Sul problematizando o trabalho doméstico (1970-1989)”, realizada com vínculo ao Programa de Pós-Graduação em História da Universidade Federal de Santa Catarina, entre 2008 e 2010, e financiada em seu segundo ano pela CAPES.
} 
feministas, as problematizações dos feminismos emergentes no Cone Sul nas décadas de $1960-70^{5}$ a respeito da naturalização do trabalho doméstico gratuito desempenhado pelas mulheres em seus lares, refletindo sobre a atualidade das questões discutidas há cerca de 40 anos atrás.

\section{Era uma vez a rainha do lar... Ou um trabalho chamado amor}

Para refletir a respeito das questões que os feminismos de Segunda Onda no Cone Sul levantaram sobre a naturalização do trabalho doméstico feminino, é indispensável pensar sobre a associação construída entre as mulheres ${ }^{6}$ e o lar. Foi ponto central, para os feminismos estudados, salientar essa associação como construída, histórica, social e culturalmente, pois isso lhes permitiu questionar tal associação e propor novas relações.

Para esta análise, acho importante trazer as matérias de destaque das publicações feministas ${ }^{7}$, por simbolizarem a importância da questão do trabalho doméstico para os feminismos estudados. No segundo número do jornal brasileiro Nós Mulheres, por exemplo, a chamada de capa (pg. 08-09) é “Dona de casa: qual o reino desta rainha?”, e a matéria principal na folha central do jornal se intitula "Nós Mulheres: donas de casa - A rainha do lar não tem cetro nem coroa...?”, a qual começa questionando: “Se fizéssemos uma gigantesca exposição, em que mostrássemos todo o trabalho invisível da dona de casa - comida, roupa lavada, fraldas, tricô, crochê e tudo o mais - em quanto seria estimado esse trabalho? Quanto vale o trabalho desvalorizado e desprestigiado da dona de casa, e quem se beneficia dele?” No também brasileiro Brasil Mulher há uma matéria de destaque no número 11 intitulada "Era uma vez a rainha do lar...” (p. 12), de uma página, que tenta descrever o dia a dia exaustivo de uma dona de casa, a dupla jornada, o acúmulo de responsabilidades.

\footnotetext{
${ }^{5}$ Os quais convencionou-se chamar de feminismos de Segunda Onda - a Primeira Onda do feminismo corresponderia às lutas sufragistas iniciadas no final do século XIX.

${ }^{6}$ É importante colocar que apesar desses feminismos já darem atenção às especificidades dentro do grupo político "mulheres", por isso o uso do plural, esta ainda era vista como uma categoria unida pela opressão em comum que sofria, e discussões sobre as diferenças entre as mulheres, de raça, etnia, classe, geração etc. não eram tão marcantes apesar de, repito, serem presentes.

${ }^{7}$ Os periódicos aqui utilizados circularam, muitas vezes com dificuldades, entre grupos de militantes feministas em seus países e às vezes fora deles, enfrentando as dificuldades que a imprensa militante em regimes de exceção costuma enfrentar. Essas fontes fazem parte do acervo do Laboratório de Estudos de Gênero e História (LEGH) da Universidade Federal de Santa Catarina (UFSC). Neste artigo utilizo os seguintes periódicos: os brasileiros Brasil Mulher e Nós Mulheres, além do Nosotras, produzido por brasileiras e latino-americanas exiladas em Paris, todos da década de 1970; os argentinos Brujas e Persona, também da década de 1970; o argentino Todas, do início da década de 1980; o brasileiro Mulherio, da década de 1980; e o paraguaio La Micrófona, o qual só tive acesso a um número, de 1990.
} 
Acho interessante refletir sobre essas publicações, pensando na utilização subversiva que elas fizeram do termo "rainha do lar”. Discussões sobre como o lar é um espaço de poder para as mulheres, são feitas em nossos dias, ${ }^{8}$ mas no período e nas fontes estudadas, o objetivo era praticamente oposto: denunciar o lar como espaço de clausura para as mulheres, que as afastava das esferas públicas de poder político e econômico. Sob essa perspectiva, o termo "rainha do lar" simbolizaria nada mais que amarras, que falta de liberdade de escolha. Aliás, a questão da liberdade de escolha surge problematizada, como por exemplo, pela espanhola Maria Angeles Duran, em obra publicada no Brasil em 1983 (p. 08): “As trabalhadoras domésticas não escolheram livremente o seu trabalho, porque não se pode chamar opção livre àquela que apresenta como alternativa aparente a renúncia ao amor, aos filhos e ao lar.”

Exemplo semelhante se encontra em um editorial do boletim internacional Isis, publicado em espanhol e com circulação considerável na América do Sul, quando afirma em seu número 11-12 de 1982 (p. 04. minha tradução)

(...) A divisão sexual do trabalho, consequência de uma hierarquia sexual, estabelecida historicamente, e acentuada pelo capitalismo ao separar drasticamente a produção de bens e serviços da vida familiar, deixou para as mulheres o trabalho de reprodução da espécie, trabalho que socialmente não se reconhece nem se valoriza, trabalho que se entrelaça com nossa vida afetiva, que se faz em nome do amor, que marca e enquadra nosso destino nas quatro paredes de uma casa. (...)

A questão da afetividade, do "trabalho que se chama amor", é muito forte nos questionamentos dos feminismos estudados, e é constantemente denunciada como responsável pela invisibilidade do trabalho feito pelas mulheres, assim como justificativa para a manutenção de sua situação. “(...) Por outro lado, é também difícil delinear com precisão o campo do trabalho doméstico, em razão de que alguns de seus limites se confundem com a expressão da afetividade, tal como ocorre quando se trata do cuidado dos filhos, esposos, atenção a doentes etc.” (TORRES, 1988, p. 05. Minha tradução.) E a questão não se encerra aí. O fato das relações de trabalho serem também relações afetivas e familiares, conforme comentam as fontes, além de ser uma espécie de elo que tornaria as mulheres e o trabalho doméstico não desvencilháveis, acabaria entrelaçando de tal forma o trabalho e a vida que, na

\footnotetext{
${ }^{8}$ Principalmente se embasando na idéia de micropoderes, mais difusos e menos estagnados que os macropoderes políticos e econômicos correntes nas discussões apresentadas pelas fontes. Um exemplo corriqueiro pode ser encontrado em SILVEIRA, 2008, pg. 55-66, quando a autora afirma a persistência das mulheres em se manterem no espaço privado por considerarem esse um espaço delas, que se por um lado as onera pelo trabalho, por outro as empodera como espaço de tomada de decisão e exercício de poder na família.
} 
experiência das mulheres, estes se tornariam uma coisa só, conforme citado por Cristina Carrasco (2008, pg. 97) atualmente, em um texto muito articulado com o ecofeminismo. Ideia semelhante é trazida por Maria Angeles Duran (1983, p. 26) décadas antes, quando afirma que “para a dona-de-casa (sic) quase não há separação entre trabalhar e viver”.

Tentando me questionar a respeito das formas como as fontes apresentam essa figura simbólica da rainha do lar, me chamaram a atenção três questões centrais: o condicionamento das mulheres à função de dona de casa; o isolamento que o lar representava para essas mulheres, principalmente para as que não tinham emprego na economia exterior; e a naturalização historicamente construída das funções domésticas femininas. São questões interligadas, nos lares e nos periódicos, mas que venho aqui tentar esmiuçar separadamente em busca de suas peculiaridades.

Sobre o condicionamento das mulheres à função de dona de casa, destaca-se a força da educação familiar, mas não apenas, na aprendizagem e aceitação de um trabalho que, segundo as reivindicações feministas, é sim qualificado e exige treino, aprendizagem.

A discriminação do trabalho, como já vimos, tem suas raízes na própria ideologia do sistema patriarcal. Uma das formas de perpetuação desta ideologia - ao lado da legislação, por exemplo - é o processo de educação. Através dele os papéis sexuais são condicionados. As meninas, educadas para a maternidade e cuidado do lar, e os meninos para atividades criativas e produtivas. (Tribuna internacional dos crimes cometidos contra as mulheres. Nosotras. Paris, $\mathrm{n}^{0}$ 25-26, 1976. p. 25.) 


\section{Imagem 1}

\section{feminita}

Querido-Papa êol:

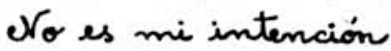
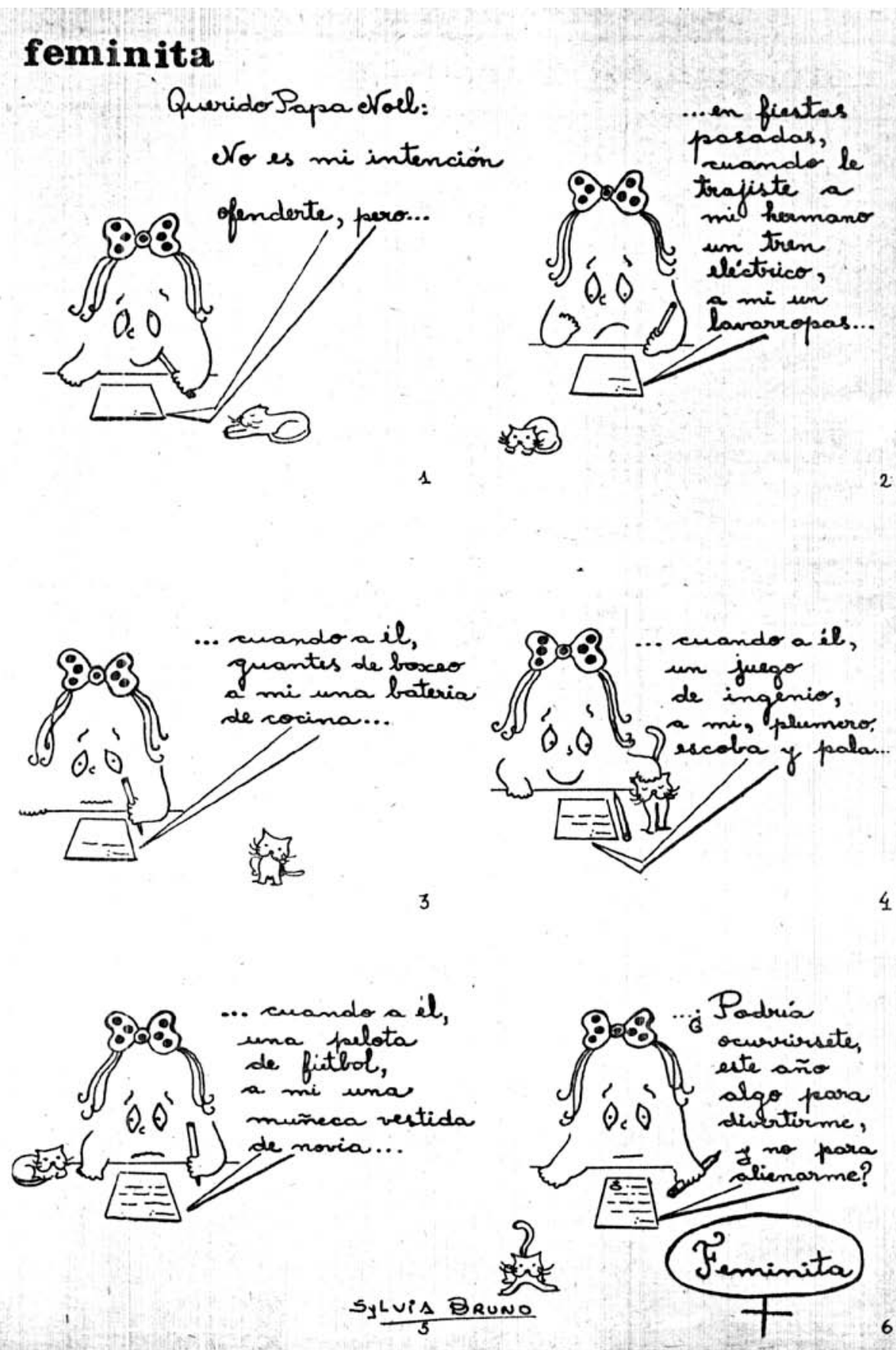

Persona. Buenos Aires, ano 1, no 3, dezembro de 1974. Pg. 21.

\footnotetext{
9 “- Querido Papa Noel: No es mi intención ofenderte, pero... en fiestas pasadas, cuando le trajiste a mi hermano un tren eléctrico, a mi un lavarropas... cuando a él, guantes de boxeo a mi una batería de cocina... cuando a él, un juego de ingenio, a mi, plumero, escoba y pala... cuando a él, una pelota de fútbol, a mi una muñeca vestida de novia... ¿Podría ocurrírsete, este año algo para divertirme, y no para alienarme?” Minha tradução: “- Querido Papai Noel: Não é minha intenção te ofender, mas... no Natal passado, quando você trouxe ao meu irmão um trenzinho elétrico, para mim trouxe uma máquina de lavar roupas... quando para ele, luvas de boxe, para mim um jogo de cozinha... quando para ele, um jogo de montar, para mim, espanador, vassoura e pá... quando para ele, uma bola de futebol, para mim uma boneca vestida de noiva... Este ano você poderia trazer algo para me divertir, e não para me alienar?”
} 
Esse processo de aprendizagem, segundo as denúncias, começaria na tenra infância das mulheres. Primeiro com brincadeiras, depois com treino mais sistematizado e gradual compromisso com tarefas específicas na casa. No terceiro número do Persona (1974, pg. 21) há uma charge criticando a educação feminina através das brincadeiras separadas por gênero, que é reproduzida acima (imagem 1). O ponto defendido é de que as mulheres não nascem assim, são educadas e precisam dessa educação para se tornarem dessa maneira, e o que a “sociedade” faz é um grande esforço para que se convença que esse é seu destino, que é um fato biológico, natural, e que não faz sentido ir contra ele.

Cristina Torres, em 1988 (p. 19, minha tradução), comenta como o processo de capacitação para o trabalho doméstico é oculto na mesma medida em que o caráter de trabalho dessa ocupação também o é:

A capacitação para o trabalho doméstico é um processo de aprendizagem que parece oculto, na medida em que o mesmo se produz no âmbito do lar. Assim como o conceito de "trabalho" o conceito de "aprendizagem" aparece fraturado em nossas sociedades: o ensino, para estar legitimado, deve se desenvolver no marco de uma instituição e por pessoal qualificado formalmente. Portanto, o treino caseiro realizado por mulheres de mais idade não é levado em conta.

A autora segue comentando, através de depoimentos, como muitas mulheres começam seu treinamento como donas de casa, ainda quando crianças, já assumindo grandes responsabilidades em idade em torno de 12 anos apenas. Seguindo a mesma linha e questionando novamente a escolha individual da trabalhadora dona de casa, Maria Angeles Duran (1983, p. 13-15) observou que as meninas já recebiam o que ela chama de "treinamento individual” para serem donas de casa muito cedo, desde muito antes dos meninos terem que escolher sua profissão e, escolher individualmente não ser dona de casa seria um caminho muito difícil a ser seguido, praticamente vetado às mulheres casadas e com filhos. Esse aprendizado faria parte do ciclo vital das mulheres, e a autora o sistematiza na infância segundo a idade das garotas (DURAN, 1983, p. 29-30) o que, ainda que seja um exercício feito se baseando no caso espanhol, ajuda a ilustrar a especialização do trabalho doméstico em qualquer lugar do mundo, inclusive no Cone Sul.

Raciocinando dessa forma, não tardam as mães, responsáveis pela educação familiar, serem apontadas como responsáveis também pela reprodução da associação entre mulheres e trabalho doméstico, assim como pela reprodução de uma dupla moral sexual - termo colocado pelas fontes - mais geral. A charge abaixo (imagem 2), retirada do quinto número do 
periódico brasileiro Mulherio (1982, p. 22), brinca exatamente com essa questão, da mãe dita conservadora reproduzindo a associação entre mulheres e trabalho doméstico em seu lar, no convívio com sua filha.

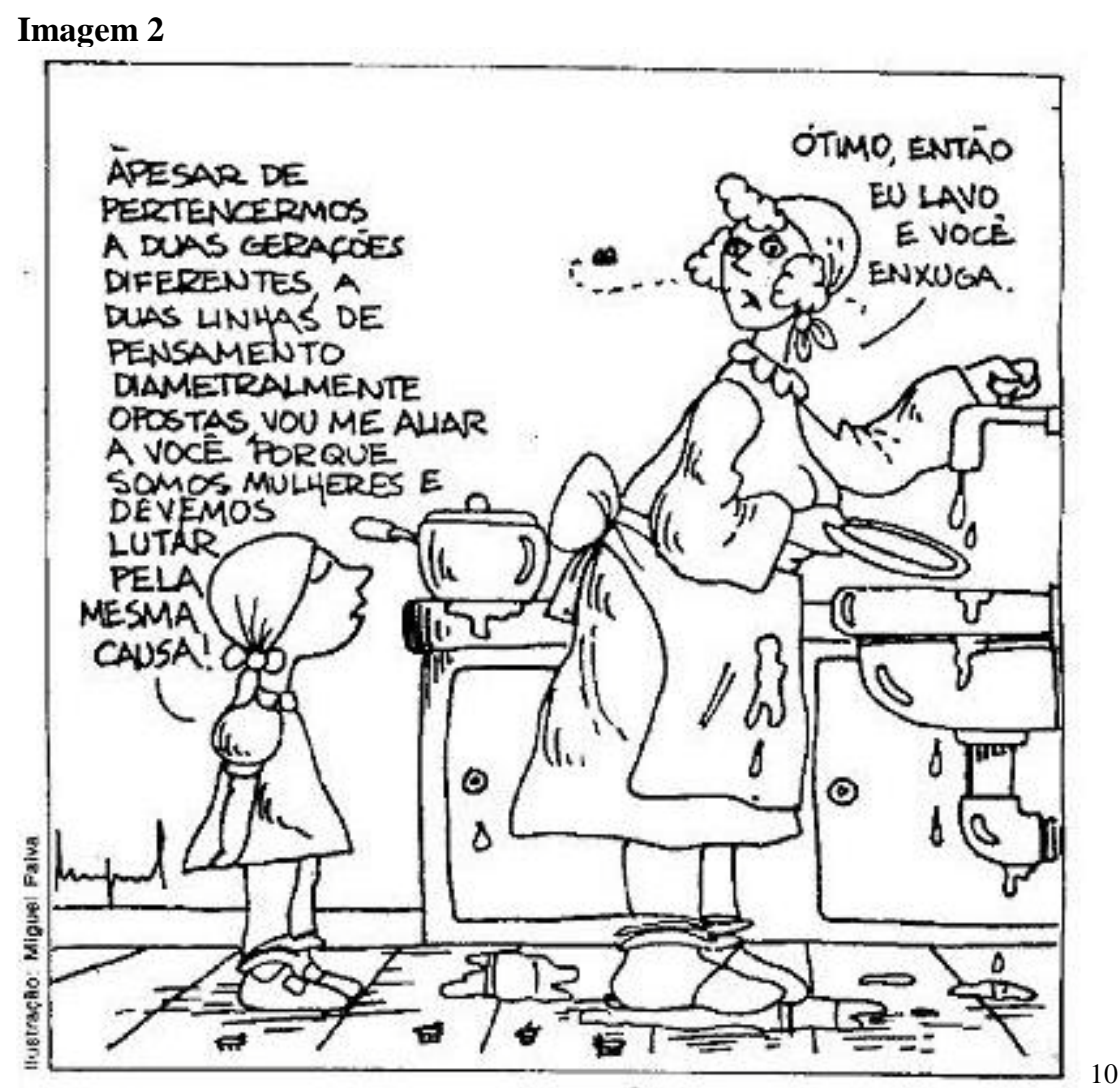

Mulherio. São Paulo, Ano 2, no 5, janeiro/fevereiro de 1982. Pg 22.

Como contraponto à ideia de mães conservadoras reproduzindo a dupla moral sexual ${ }^{11}$ nos lares, temos um interessante artigo intitulado Bíblia feminista para culpar mãe, de Rosa Escarlate, retirado também do Mulherio (1985, p. 04-05), em seu vigésimo terceiro número. Nele, a autora faz uma crítica angustiada ao livro Educar para a Submissão, da italiana Elena Belotti, que se tornou um best-seller da produção feminista. A obra que procura mostrar a participação das mães, como educadoras, na reprodução de valores tradicionais sexistas e excludentes, é criticada por Rosa Escarlate, uma mãe feminista (a qual, aliás, adorava o livro) que percebe que a educação, os gostos e a constituição de sua filha e seu filho como

\footnotetext{
10 “- Apesar de pertencermos a duas gerações diferentes, a duas linhas de pensamento diametralmente opostas, vou me aliar a você porque somos mulheres e devemos lutar pela mesma causa! - Ótimo, então eu lavo e você enxuga."

${ }^{11}$ A noção de dupla moral sexual está ligada aos diferentes valores culturalmente difundidos e aceitos para homens e mulheres, quer dizer, a ideia de que as regras de comportamento em sociedade difeririam conforme $o$ gênero ou, segundo as discussões do período observado, conforme o sexo.
} 
indivíduos não são processos os quais ela possa controlar absolutamente, e que transformações gerais na sociedade são necessárias para que transformações efetivas no desenvolvimento das crianças sejam possíveis. Novamente no Mulherio, no número 36 (1988, p. 02), encontramos uma carta de leitora que questiona um artigo do número 33 do periódico, uma vez que entende que o artigo reforça a ideia de que a socialização das crianças seria tarefa exclusivamente feminina. Quer dizer, mesmo dentro do recorte dos feminismos estudados, que apresentam inúmeras semelhanças, as posições não são unívocas, e encontramos conflitos e disputas. Nesse sentido o Mulherio é uma fonte interessante por aceitar colaborações de pessoas que não faziam parte do coletivo editorial, de forma que diferentes opiniões sobre temas semelhantes são expostas, como é o caso também de boletins que fazem uma espécie de coleta de artigos de diferentes publicações em diferentes países, como o Isis e o Mujer Ilet.

Outro contraponto oferecido à ideia de que a socialização das crianças seria tarefa feminina pode ser observado em questionamentos sobre como as escolas e os meios de comunicação, entre outros “formadores sociais”, reproduzem a dupla moral sexual e associam as mulheres à esfera doméstica desde muito cedo. Helena Hirata (1986, p. 66) observa, em pesquisa no Japão, mas que cabe às críticas feministas realizadas no Cone Sul, e voltada à questão da linguagem como esfera reprodutora de diferenças de sexos e de classes, que

Essa divisão do trabalho segundo os sexos, indicada no nível da linguagem, é praticada desde o nascimento, pontuada por ritos e marcada por inumeráveis símbolos.

Com efeito, a aceitação e a interiorização da divisão sexual do trabalho, tanto entre trabalho doméstico e trabalho assalariado quanto no seio mesmo do trabalho assalariado, são o objetivo da socialização inicial das crianças. Essa educação é condição prévia da aceitação e interiorização mesmas da autoridade mediante aprendizado, na escola, das formas de linguagem diferenciadas de acordo com o estatuto social do emissor e do receptor.

A imagem abaixo (imagem 3), retirada do sexto número do periódico feminista paraguaio La Micrófona (1990, p. 10), aponta para essa questão, para a reprodução da dupla moral sexual na educação formal. O livro e a carteira insinuam que as crianças estão na escola, e o balão com seu pensamento vem trazer o conteúdo do livro, em crítica ao que é passado como padrão de normalidade em grande parte dos livros didáticos, seja através de textos ou ilustrações: o pai, enaltecido - no caso como super-herói - por participar da esfera pública, e a mãe em casa com o filho esperando sua volta. 


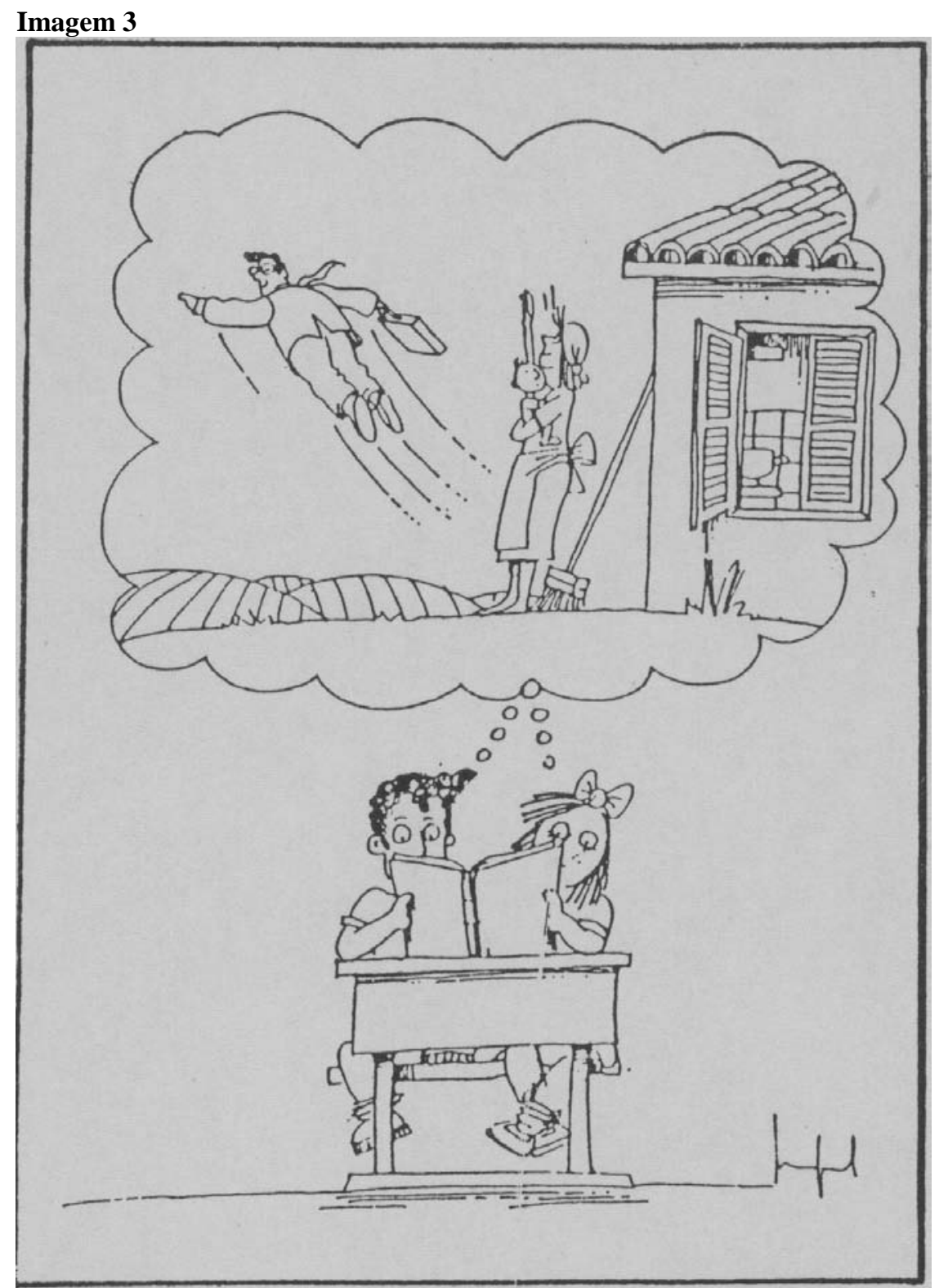

La Micrófona. Asunción, Ano 1, nº 6, junho de 1990. Pg. 10.

Outro exemplo de crítica a livros didáticos pode ser encontrado no quarto número do Mulherio (1981, p. 20). Célia Chaim, comentando estudo de Maria Luísa Eluf sobre os livros escolares de Educação Moral e Cívica, Estudos Sociais e Organização Social e Política, fala como mesmo nas brincadeiras infantis, nesses livros, já se ilustravam as divisões de esferas, espaços e comportamentos tradicionalmente aceitos como masculinos e femininos. Comenta também, como o ensino programado, aquela prática de preencher lacunas em frases, reafirma as diferenças de oportunidades entre homens e mulheres, como por exemplo: “'Qual a profissão do papai?..... ' ‘A mamãe cuida..... da casa' (o espaço pede como complemento as palavras 'das tarefas')” Além da questão de reprodução da moral conservadora e excludente, a autora se preocupa com o fato desses modelos não corresponderem à realidade de grande 
parte das crianças, gerando dúvidas e contradições que poderiam prejudicar seu desenvolvimento.

A imagem abaixo, (imagem 4), retirada do Mulherio, é emblemática pelo texto que traz consigo, mas principalmente pelas imagens que, não bastando mostrar a mãe cuidando da roupa enquanto o pai examina algum documento no escritório, faz essa divisão também entre as crianças, ilustrando a menina com um espanador de pó na mão enquanto os meninos leem.

Imagem 4

\section{Em casa,}

\section{quem manda \\ é o papai}

Os livros de Moral e Civismo adotados

nas escolas de $1^{\circ}$ grau reforçam a

rígida e tradicional divisão de papéis entre homens e mulheres.

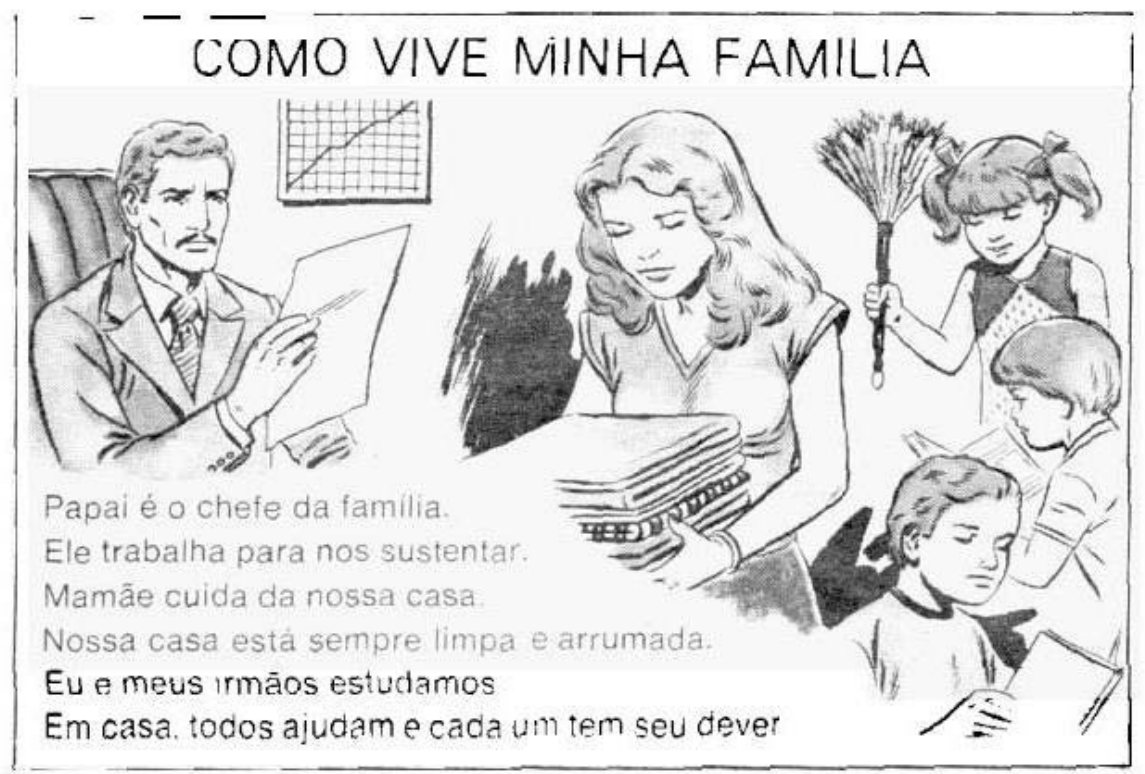

Mulherio. São Paulo, Ano 1, no 4, novembro/dezembro de 1981. p. 2.

\footnotetext{
${ }^{12}$ Ilustração extraída de "A criança, a família, a escola”, livro de Estudos Sociais para a $1^{\text {a }}$ série, de Yolanda Marques, publicado em 1981 pela Companhia Editora Nacional. Redação da ilustração: "Papai é o chefe da família. Ele trabalha para nos sustentar. Mamãe cuida da nossa casa. Nossa casa está sempre limpa e arrumada. Eu e meus irmãos estudamos. Em casa, todos ajudam e cada um tem seu dever.”
} 
Ainda no Mulherio (1981, p. 21), encontramos uma crítica de Fúlvia Rosemberg à “Coleção Ternurinha para Colorir”, que era vendida nas bancas no Brasil na década de 1980. No exemplar observado, retrata-se o dia a dia de uma criança muito pequena, uma menina que usa todo seu tempo livre (fora da escola) com afazeres domésticos. Repara-se que o contato da criança com a escola não ganha atenção na história contada, e a ênfase que se dá ao trabalho doméstico é muito grande. Reproduzo a pequena matéria abaixo (imagem 5), pois a aparência da criança e seu entusiasmo ao limpar a casa são alvos da crítica de Fúlvia Rosemberg.

\section{Imagem 5}

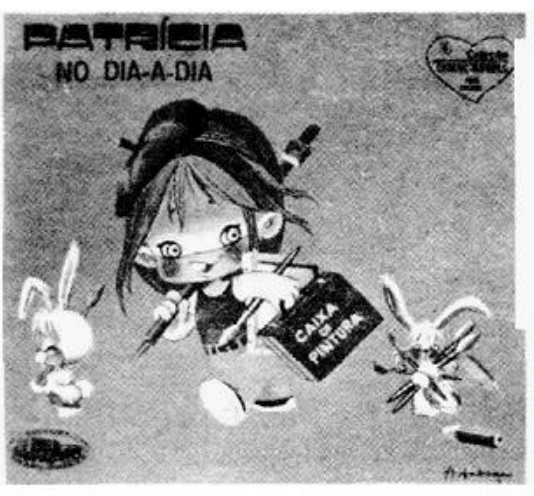

De mãe

Outro dia, procurando numa ban. ca de jornal uma revista para as crian ças, encontrei Patricia no dia-a-dia, mas cujo título verdadeiro deveria ser: como ensinar, brincando, que a felicidade da mulher provem da dupla jornada de trabalho.

Patricia, menina bem pequena abre o llvro apresentando seu diário: "Hoje acordel cedinho e glegre. Pulei da cama e escovel os dentes. Coloque um vestido leve, pois vou arrumar a casa". Até aqui a ilustração é fiel ao texto: Patrícia se espreguiça na cama, está no banheiro escovando os dentes, retira um vestido do guarda-roupa.

A seguir, a tragédia do condicionamento precoce se instala, texto e ilustração se contrapondo, com uma aparência esquizofrênica mas de um ve rismo ldeológico lascinante, compará. vel apenas a melhores produçóes do realismo socialista, capaz de arrebatar
Patrícia no dia-a-dia

de Arthur Henrique Brage.

Coleçăo Ternurinha para colorit

Editora Brasil-Amórica

EBAL, Cr\$ 80,00.

\section{para filha}

um comentarto semelhante ao eloglo a flor de plástico: é tảo perfeita que até parece de verdade

Patrícia: "O día está lindo! Tenho multa coisa vara fazer hote". Fantasie-

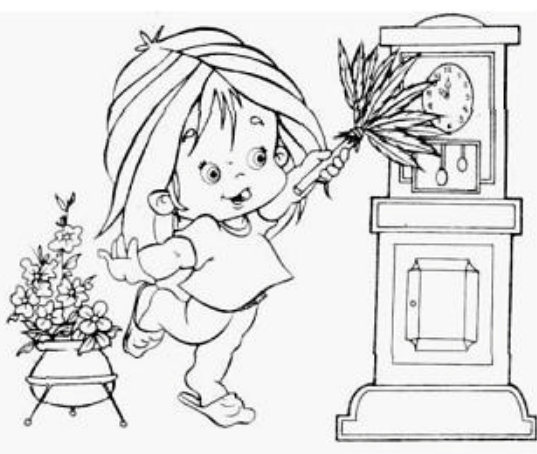

Acabando aqui, vou laver 25 roupas da boneca Iiloca mos o horizonte Imaginárlo de uma criança bem nutrida, e ainda por cima heroina de livro. O que poderá ser "esta muita colsa para fazer"? Fazer bola de sabăo, arrellar o irmão, virar cambalhota, passear na rua, tomar sorvete, andar de elevador, virar astronauta? Isto é o que você pensa. Patrícia pega a vassoura e faz uma faxina geral na casa. Espana, cozinha, rega as plantas e não se esquece de sua Liloca: "Quero ser tão boa para Liloca quanto mamãe e para mim". :

O que vemos? Abraços, beijos, afagos e brincadelras?

An, An! Amor materno como bem se sabe, é desdobrar ftbra por flbra a musculatura dos braços. Patricla, na llustraço lava a roupa da bonecy Llloca! "Depols de tanta trabalhelra, "Uf! que cansaço! Vou parar um pouco antes de estudar".

E al começa a preparaçăo da se gunda jomada de trabalho alem da lição de casa, o culdado com o corpo "gosto de ir á escola, bem limpinha e cheirosinha!"). Da escola, nada se sa be, apenas se vé Patricia saindo de casa preocupada, como uma verdadeira mulherzinha: "FL meus deveres com capricho Sera que Tia Regina vai gostar?" E em seguida a volta para o lar botar as crlancas para dormir ("Vamos. Llloca! Está na hora de dor. mir" e o formidável comentário final "Meu diario Hoje fol um dia feliz! Como é bom estar em casa'.

Patrícias de todo o mundo Sabote mos a Ternurinhat

\section{Fúlvla Rosemberc}

Mulherio. São Paulo, Ano 1, nº 4, novembro/dezembro de 1981. g. 21.

As críticas aqui apresentadas ao condicionamento das mulheres aos afazeres domésticos se preocupam, portanto, com a falta de possibilidade de escolha pessoal destas em executar ou não esse trabalho, devido imposições que ocorreriam tanto dentro dos lares como no “mundo lá fora”, em seus processos de socialização. Ao mesmo tempo, essas críticas vêm 
mostrar que esse trabalho, o qual é tido como corriqueiro, no sentido que pode ser feito por qualquer pessoa e principalmente por qualquer mulher, não é um dom natural das mulheres ou parte "essencial” da feminilidade, sendo um trabalho que exige treino e qualificação, que se dá entre as meninas desde cedo.

Maria Angeles Duran (1983, p. 59-61), sobre a qualificação do trabalho da dona de casa, comenta que aprender o que pode ser considerado básico, nesse trabalho, de fato não levaria muito tempo (ela calcula entre três e seis meses); mas se aprimorar levaria anos, quer dizer, requer muita qualificação. Usa a comparação entre um aprendiz e um chefe de cozinha para mostrar o quanto a dona de casa pode se aprimorar em suas funções. Cita especificamente o cuidado com as crianças como uma das atividades domésticas que mais exige preparo e qualificação, e lembra que as habilidades e atividades podem diferir conforme o grupo social no qual a dona de casa está inserida. Também traz a hipótese de que, como o trabalho doméstico é muito efêmero, se aprimorar nele poderia ser uma busca por prestígio, uma maneira de fazer com que esse trabalho seja lembrado, mesmo que seus resultados já tenham se extinguido.

A próxima questão que gostaria de comentar, no que se refere às problematizações feministas a respeito do "título" rainha do lar, é o isolamento. Em seu primeiro número, o periódico Persona problematiza o isolamento que sofrem as donas de casa, questão também presente no segundo número do jornal Nós Mulheres:

(...) As mulheres, cada uma "rainha do lar", dispersas em suas casas e suas famílias, vivem em um isolamento que as impede de reconhecer nelas mesmas e em suas irmãs a exploração a que são submetidas. Perdidas nas células incomunicáveis das famílias têm como único meio de contato com o mundo o homem esposo, pai ou filho. Por isso a mulher não aparece na história escrita, mas sem ela os homens não poderiam ter feito a história. (Persona, 1974, p. 27. Minha tradução.)

Quando a gente fica fechada, pensa que o problema é só da gente. Mas no momento em que passa a conversar mais com outras donas de casa, a gente vê que o problema é geral. É geral na classe média, é geral na classe baixa, é geral... Inês, 50 anos, 3 filhos (Nós Mulheres, 1976, pg. 08).

A questão do isolamento das donas de casa se articula com o fato delas serem trabalhadoras ao mesmo tempo em que são membro de uma família, de forma que seus universos pessoal e laboral se fundem, tanto fisicamente quanto psicologicamente. Maria Angeles Duran (1983, p. 63-66), pensando esta questão, subdividiu esse isolamento em físico, psicológico, organizativo e político. O isolamento físico, talvez o mais evidente, se refere ao 
fato do trabalho se dar em "unidades econômicas isoladas". Tendo uma necessidade de disposição constante, ao mesmo tempo em que é um trabalho individual e solitário, artifícios como compras diárias no mercado são utilizados para fugir desse isolamento, mesmo que se traduzam em maior volume de trabalho. As conversas com vizinhas, por exemplo, são equiparadas às relações laborais de operários, e são consideradas pela autora como importante válvula de escape para o isolamento físico.

Em seguida, Maria Angeles Duran comenta o isolamento psicológico, resumindo a questão na seguinte afirmação: “(...) o papel social da mulher e, sobretudo, da dona-de-casa (sic), consiste em dar-se aos demais, em atender a suas necessidades físicas e afetivas. (...) Sua afirmação pessoal consiste precisamente em negar-se.”

O isolamento organizativo parece ser um resultado do isolamento físico e psicológico.

A dona-de-casa (sic) tem mais dificuldades que qualquer outro trabalhador para organizar-se e defender suas reivindicações: isto se deve ao seu isolamento nas unidades domésticas, mas mais ainda à sua condição de trabalhadora "permanente", sem tempo para dedicar a suas próprias atividades e à definição moral de suas obrigações como trabalhadora doméstica. (p. 64)

A autora observa ainda que, diferente de outros/as trabalhadores/as, a dona de casa não pode se dar conta que é explorada ou que sua relação de trabalho é injusta sem que isso afete intimamente suas relações pessoais. Se há problema com o trabalho, a esfera pessoal não pode ser um refúgio.

Sobre a questão do isolamento político, a autora comenta que “As relações políticas são expressões das relações de poder e a dona-de-casa (sic) está excluída do poder e da política” (pg. 65). O isolamento físico, a separação marcada de esferas pública e privada, o fato de não se admitir que a economia doméstica é parte integrante e indispensável para a economia de forma geral, são fatores que contribuem para que a política “exterior” não se preocupe com o que ocorre nos lares, excluindo dessa maneira as donas de casa de suas pautas.

Duas cartas de leitoras do Mulherio (1981, p. 02), ambas retiradas de seu quarto número, expressam experiências em que vemos mesclados esses isolamentos observados por Maria Angeles Duran.

Sou ouvinte assídua da TV Mulher. Como dona-de-casa (sic), este programa veio de encontro a um anseio que sempre tive, no sentido de melhor aproveitar as horas em que estou na cozinha preparando o almoço da família. TV Mulher me põe em contato com o mundo e me sinto irmanada a milhares 
de mulheres que, mesmo como donas-de-casa, vivendo uma vida um tanto delimitada, tem (sic) vontade de participar do que vai por aí, ter uma visão de conjunto de tudo. (...) Maria Luísa Schroeder, Cruza Alta, RS.

(...) Foi e está sendo muito difícil ser só mãe, dona-de-casa (sic), esposa. É muito difícil pra mim não estar lutando, estar longe das pessoas e do mundo lá fora. Dá uma sensação de inutilidade, de alienação. Às vezes, até de solidão. Dá uma vontade de sair correndo, de procurar alguém pra conversar. Falar sobre qualquer coisa, mas falar e ser ouvida, e ouvir também. (...) Maysa V. B. Francisco, Moóca, São Paulo, SP.).

Os depoimentos das cartas nos fazem refletir a respeito da necessidade de contato com o mundo exterior, expresso de forma marcante. A sensação que se passa, ou a ideia que se reforça, é a de que "as coisas" acontecem lá fora, e a dona de casa precisa ao menos se informar sobre essas coisas, quando não pode participar delas, buscando fugir da alienação. Talvez o trabalho doméstico não afaste mais as trabalhadoras de acontecimentos públicos, políticos ou econômicos, que o trabalho em um fábrica ou outra unidade de produção que também isole seus trabalhadores. Mas a falta de convívio entre a “categoria”, por assim dizer, acaba reforçando a ideia de alienação e despertando nas trabalhadoras uma vontade muito maior de contato com a esfera pública.

Esse isolamento, e as angústias e tensões decorrentes dele, se transformam em respostas físicas nos organismos das trabalhadoras. Com relação específica à questão do isolamento e solidão, citam-se a depressão e o alcoolismo. O periódico argentino Todas (1980, p. 33), em 1980, comenta: “17-01-80: Na Itália, um estudo estatístico revelou que donas de casa tendem a beber. As causas desse fenômeno são, de acordo com a opinião dos psicólogos, o tédio e a solidão.” O Mulherio, em seu nono número (1982, p. 22), apresenta notícia semelhante, divulgando relatório da Organização Mundial da Saúde publicado em Genebra:

O protótipo da mulher alcoólatra, afirma o estudo, é a dona-de-casa (sic) com dois ou três filhos, na faixa de 40 anos de idade. Essas mulheres são chamadas de "as bebedoras das nove às três" - referindo-se ao horário em que elas, sós em suas casas, fazem frente como podem à depressão, à ansiedade e à frustração.

E o artigo continua: “(...) 'A solidão da dona-de-casa (sic), unida a um trabalho que pode ser tão esgotante quanto não valorizado, é um dos fatores determinantes do alcoolismo’ $(\ldots) "$

A última questão a ser tratada nesse item, após observar a formação das mulheres como donas de casa e o peso que seu trabalho no lar representa, é central nas críticas dos 
feminismos de Segunda Onda: a naturalização da função doméstica feminina. A ideia de que o trabalho doméstico é trabalho de mulheres, seja porque elas têm "maior facilidade”, "mais jeito", ou mais habilidade com ele, seja porque "sempre foi assim” e seria um insulto à masculinidade homens fazerem esse tipo de trabalho, é denunciada pelos feminismos como uma tentativa (bem sucedida, aliás) de indicar como natural uma associação que é historicamente construída, e precisa ser reafirmada constantemente no dia a dia para manter sua legitimidade.

Mirta Henault, em 2001 (p. 23), afirma que:

A cultura (as culturas) reconhece na mulher qualidades supostamente inatas. Parece tão naturalmente natural que uma mulher realize trabalhos domésticos, sirva à família, faça a comida diária, teça um agasalho ou trabalhe por salário em tarefas de serviço, como que tenha quadris largos e seios desenvolvidos. E isto, segundo a mesma cultura, ocorre desde sempre e ocorrerá para sempre, "naturalmente”.

Ou seja, essa não é, absolutamente, uma questão superada pelos feminismos em nossa década. Uma das estratégias para combater a naturalização do trabalho doméstico feminino, datada do período das fontes, parte de críticas de economistas feministas que, ao defender que essa naturalização serve a interesses econômicos do sistema capitalista, justificam o esforço de instituições conservadoras na manutenção da tradicional divisão sexual do trabalho. Quer dizer, as mulheres como reprodutoras da força de trabalho e também como mão-de-obra de reserva, “cargos” que só podem ser ocupados se mantida a divisão sexual do trabalho, seriam indispensáveis à manutenção do sistema. Maria Angeles Duran (1983, p. 09), como economista, comenta

(...) a dúvida sobre a condição 'natural' da mulher como dona-de-casa (sic) não é uma questão sem importância, uma vez que supõe pôr em dúvida, precisamente, os alicerces econômicos de nossa própria sociedade. É ainda mais grave e mais arriscado do que questionar a propriedade privada (...)

O periódico argentino Brujas (1984, p. 10-11. Minha tradução, os grifos não.), em artigo intitulado "El feminismo como ideologia y como practica politica", de 1984, afirma também nesse sentido

(...) A respeito do trabalho doméstico, existem numerosos estudos feministas, que - com algumas divergências teóricas acerca do caráter desta produção - concordam em afirmar que se trata de um trabalho produtivo realizado gratuitamente pelas mulheres no seio da família e cujo caráter de 
trabalho se faz "oculto" por uma visão naturalista que o considera uma tarefa "natural” das mulheres. -

Economistas do Terceiro Mundo e feministas descobriram que a acumulação capitalista resultante da mais-valia (aquela extraída exclusivamente do trabalho mercantil) se alimenta também na acumulação permanente de base, ou seja, aquela baseada na exploração do trabalho doméstico não mercantil realizado pelas mulheres no lar, trabalho que permite a produção e reprodução da força de trabalho do marido e filhos a menor custo. -

Por fim, todos esses estudos colocam em evidência que a produção doméstica é uma categoria econômica e não uma fatalidade biológica. (...)

Apesar das críticas, admite-se a dificuldade em se lidar com padrões tradicionais de comportamento, pela força ideológica que mostram ter. Mesmo feministas, engajadas na luta pela igualdade, acabam assumindo para si as obrigações domésticas, como comenta Dominique Fourgeyrollas-Schwebel em 1999: “Assim, estimuladas por sua concepção de limpeza e ordem, inúmeras mulheres se encarregam da maior parte das tarefas domésticas, apesar do ideal igualitário que reivindicam”. É uma divisão de tarefas bem clara, na qual o homem geralmente “dá uma ajudinha”, e a falsa ideia de uma divisão mais justa das tarefas só contribui para a manutenção da situação de desigualdade. A autora explica isso através do conceito da "lógica do dom” 13 , no qual as mulheres, tão condicionadas, desde crianças ensinadas a ter certo tipo de comportamento, e convencidas de que tal comportamento é algo natural a elas, acabam assumindo tais obrigações como naturais e estruturando a divisão de tarefas no lar. Às mulheres que trabalham fora de casa cabe racionalizar seu tempo para terem condições de conciliar as duas jornadas de trabalho, ou contratar alguém para ajudá-las.

Essa ideia de "lógica do dom” se constrói baseada na naturalização do trabalho doméstico feminino, e o papel familiar das mulheres e, em especial, a maternidade são apontadas como as grandes vilãs dessa questão. Bibliografia recente coloca que "Desde a década de 1960, nos EUA e em outros locais, quando as feministas afirmaram que 'o pessoal é político', muitos consideraram seriamente o papel da família na subjugação das mulheres.” (GORNICK; MEYERS, 2007, p. 195) Vale ressaltar que essas críticas se dão muito mais na preocupação com a obrigatoriedade do casamento e da maternidade do que com propostas que neguem essas instâncias. Por exemplo, no artigo intitulado "Ser mujer - ¿Destino o decisión?”, do primeiro número do Persona, de 1974 (p. 28-31), afirma-se que “A mulher não é uma criatura que tem que se converter em mãe; é a criatura que pode ser mãe.” Ideia semelhante é encontrada no primeiro número do $\underline{\text { Mulherio, }}$ de 1981 (p. 08), onde se afirma

\footnotetext{
${ }^{13}$ Um exemplo de conceito semelhante a este pode ser encontrado em Danièle Kergoat (1986, p. 88), quando ela fala de uma "ideologia do dom”, ideologia naturalista a qual acredita em uma ordem natural das coisas, e abriria perspectiva para a reprodução de todas as opressões (sexismo, racismo...).
} 
que "Quando se questiona a maternidade compulsória, quando se reivindica o direito inalienável da mulher ao controle do seu próprio corpo, o que se postula, evidentemente, não é a não-maternidade igualmente compulsória.”

\section{E a discussão não se encerra...}

Nos países estudados percebemos diferenças, assim como nos 20 anos de recorte da pesquisa que gerou esse trabalho. As preocupações das teóricas feministas no começo da década de 1970, sobre o trabalho doméstico, se mostram em muitos pontos diferentes das preocupações observadas no final da década de 1980. No mesmo sentido, podemos notar diferentes temporalidades das discussões entre os países. Quer dizer, essas discussões não chegam todas juntas, ao mesmo tempo, em todo o Cone Sul. Questões tratadas no começo da década de 1970 na Argentina ou Brasil podem ser encontradas no final da década de 1980 no Uruguai ou Paraguai. Não que na década de 1980 essas questões tenham desaparecido das publicações brasileiras e argentinas, mas elas perdem força enquanto outras questões se sobressaem. Assim, perceber essas questões se torna um exercício, tanto ao lidar com as permanências e mudanças, quanto com as diferentes temporalidades das discussões nos países observados.

De uma forma ou de outra, o que fica evidente é a persistência, ainda que com algumas transformações, dessas questões. Quando Maria Lucia da Silveira escreve, em 2008 (pg. 55-66), que “Trata-se de problematizar a coletivização das tarefas, a ponto de transformálas numa questão política”, ela parece estar fazendo eco às questões levantadas pelos feminismos de Segunda Onda há 30 ou 40 anos atrás. A mesma atualidade pode ser encontrada na observação de Fanny Tabak, datada de 1983 (p. 70) e reproduzida abaixo

O trabalho doméstico continua a pesar sobre os ombros da dona-de-casa (sic) brasileira, a quem cabe enfrentar - quando trabalha no mercado externo - a dupla jornada. Os equipamentos coletivos (...) constituem antes a exceção, do que a regra.

Estas questões continuam em aberto. Recentemente, podemos observar na imprensa, e não só na feminista, notícias sobre estudos referentes ao trabalho doméstico. É o caso do jornal O Globo, que em 2006 (p. 35) publicou matéria em que coloca que se o trabalho doméstico fosse contabilizado no PIB, equivaleria a 12,76\%. Isso correspondia, naquele ano, 
ao PIB do estado do Rio de Janeiro, que no Brasil só perde para o estado de São Paulo, e é maior que o PIB produzido pela agricultura no país, que gira em torno dos $10 \%$ do total.

Faz-se importante citar exemplos recentes para se entender a pertinência de se discutir tal questão. Observa-se como a questão dos trabalhos de cuidados persiste, ainda que de maneira transformada, e ganha ênfase na atualidade

As necessidades de cuidados são cumpridas cada vez com maiores dificuldades pelas famílias, isto é, pelas mulheres, quando não recebem cobertura de serviços proporcionados pelo mercado ou fornecidos pelo Estado. O trabalho de cuidados supõe em nossos países não só cuidar dos filhos e do parceiro, também pode implicar o cuidado dos pais e dos netos que vivem na mesma habitação ou em habitações separadas. (AGUIRRE; BATTHYÁNY, 2007, p. 20)

E como soluções, indicam-se a importância das pesquisas e das ações coletivas resultantes destas, atentando para as posturas ideológicas contidas nessas pesquisas.

Todavia, o problema maior ainda é a ausência de diagnósticos e propostas de políticas adequadas às novas realidades em que vivem as famílias nas sociedades em transição e contínua mudança. É preciso destacar, no entanto, que na década de 1990 se assistiu à grande inovação que foi a colocação em debate público de um tema até então ignorado: a violência doméstica e intrafamiliar, bem como a recomendação de medidas políticas para enfrentála. Não obstante, outros temas centrais para a família não mereceram a mesma atenção, como é o caso da dupla jornada da mulher que trabalha; da situação das famílias migrantes e deslocadas; da paternidade responsável e do cuidado de crianças, idosos e portadores de necessidades especiais, entre muitos outros problemas que as famílias latino-americanas enfrentam na atualidade. (ARRIAGADA, 2007, p. 250)

Logo, se não se dá atenção aos lugares diferentes que mulheres e homens ocupam em nossas sociedades, se ignoram os papéis diferenciados e as responsabilidades e capacidades determinadas socialmente para os dois gêneros, então é possível que uma política aparentemente neutra acarrete resultados diferenciados para cada um dos gêneros. É nesse sentido que as políticas não podem ser consideradas neutras, e sim, em vez disso, "cegas ao sexo". (CARRASCO, 2008, p. 102)

Também se guiando pelo o que pode ser entendida como uma perspectiva de gênero ${ }^{14}$ - partindo de um olhar mais relacional, não como sinônimo de sexo como Cristina Carrasco coloca acima -, podemos refletir sobre as atuais contribuições masculinas nos lares, as quais

\footnotetext{
${ }^{14}$ Lembrando que o conceito de gênero, relacional, que se desenvolve a partir da proposição de Joan Scott (SCOTT, 1990), não está presente nas fontes dos anos 1970-80, e que o que tento fazer é pensar como as problematizações de sexo dos feminismos de Segunda Onda podem contribuir para nossas atuais problematizações de gênero da questão. Daí a tentativa de diálogo com diferentes temporalidades.
} 
geralmente se dão em atividades domésticas “hierarquicamente elevadas”, por assim dizer. Ou seja, os homens têm sim ajudado mais nos afazeres domésticos, mas isso geralmente ocorre em tarefas mais valorizadas, ou por lidarem com a educação das crianças (brincar com elas, trazer da escola etc.), ou por envolverem maior criatividade (como é o caso de cozinhar, se comparado com tarefas usuais de limpeza). Este e outros fatores, aqui apresentados, nos levam a assinalar a força das relações desiguais de gênero nos lares, a sua persistência, e o entendimento de que o problema da distribuição desigual do trabalho doméstico e das tarefas de cuidados é um problema de gênero, é uma questão de gênero.

\title{
NATURALLY A FEMALE LABOUR?: Feminist discussions in the Southern Cone (1970-1990)
}

\begin{abstract}
The relation between women and housework, even though affirmed by the feminisms and the gender studies as culturally built, has its main contribution in the naturalization of these functions. In this article I have the purpose of writing a history of the discussion about the naturalization of the housework in the Second-wave feminisms of Southern Cone, using as source the printed production of these feminisms, mostly periodicals. It is important to note that the specified period is given by the sources I have used and, through them, I intend to settle this discussion starting from a historiographic perspective inserted in the feminist and gender studies, with the support of bibliography contemporary to the utilized documents and current bibliography.
\end{abstract}

Keywords: Housework. History of Feminism. Second-wave Feminism. Southern Cone. Feminist Press.

\section{Referências}

AGUIRRE, Rosario; BATTHYÁNY, Karina. Introducción. In: GUTIÉRREZ, María Alicia (org). Género, familias y trabajo: rupturas y continuidades. Desafíos para la investigación política. Buenos Aires: CLACSO, 2007.

ARAÚJO, Clara; SCALON, Celi (orgs). Gênero, família e trabalho no Brasil. Rio de Janeiro: FGV, 2005.

Brasil Mulher. São Paulo, ano 3, nº 11, 1978.

Brujas. Buenos Aires, Ano 2, nº 6, 1984. 
ARRIAGADA, Irma. Estruturas familiares, trabalho e bem-estar na América Latina. In: ARAÚJO, Clara; PICANÇO, Felícia; SCALON, Celi (orgs). Novas conciliações e antigas tensões? Gênero, família e trabalho em perspectiva comparada. Bauru: Edusc, 2007.

BEDREGAL, Ximena. Con mi feminismo mirando al Sur. Disponível em http://www.creatividadfeminista.org. Acesso em 15/03/2007.

CARRASCO, Cristina. Por uma economia não androcêntrica: debates e propostas a partir da economia feminista. In: SILVEIRA, Maria Lucia da; TITO, Neuza. Trabalho doméstico e de cuidados. Por outro paradigma de sustentabilidade da vida humana. São Paulo: SOF, 2008.

DURAN, Maria Angeles. A dona de casa: crítica política da economia doméstica. Rio de Janeiro: Edições Graal, 1983.

FOURGEYROLLAS-SCHWEBWL, Dominique. Trabalho doméstico, serviços domésticos. In: FARIA, Nalu; NOBRE, Miriam (orgs). O trabalho das mulheres: tendências contraditórias. São Paulo: SOF, 1999.

GORNICK, Janet C.; MEYERS, Márcia K. Regimes de bem-estar social com relação a trabalho remunerado e cuidados. In: ARAÚJO, Clara; PICANÇO, Felícia; SCALON, Celi (orgs.). Novas conciliações e antigas tensões? Gênero, família e trabalho em perspectiva comparada. Bauru: Edusc, 2007.

HENAUT, Mirta. De la rueca a la red. La economia sumergida. Buenos Aires: Ediciones Corregidor, 2001.

HIRATA, Helena. Vida reprodutiva e produção: família e empresa no Japão. In:

KARTCHEVSKY-BULPORT, Andrée (et. al.). O sexo do trabalho. Rio de Janeiro: Paz e Terra, 1986.

KERGOAT, Danièle. Em defesa de uma sociologia das relações sociais. Da análise crítica das categorias dominantes à elaboração de uma nova conceituação. In: KARTCHEVSKYBULPORT, Andrée (et. al.). O sexo do trabalho. Rio de Janeiro: Paz e Terra, 1986.

La Micrófona. Asunción, Ano 1, nº 6, junho de 1990.

Mulherio. São Paulo, Ano 1, nº 1, maio/junho de 1981.

Mulherio. São Paulo, Ano 1, nº 4, novembro/dezembro de 1981.

Mulherio. São Paulo, Ano 2, nº 5, janeiro/fevereiro de 1982.

Mulherio. São Paulo, Ano 2, nº 9, setembro/outubro de 1982.

Mulherio. São Paulo, Ano 5, nº 23, outubro/novembro/dezembro de 1985.

Mulherio. São Paulo, Ano 8, nº 36, janeiro de 1988.

Nós Mulheres. São Paulo, nº 2, setembro/outubro de 1976. 
Nosotras. Paris, $\mathrm{n}^{\circ}$ 25-26, 1976.

O Globo. Rio de Janeiro, primeiro caderno, 05 de março de 2006.

PEDRO, Joana Maria. Narrativas fundadoras do feminismo: poderes e conflitos (1970-1978). Revista Brasileira de História. São Paulo: ANPUH, vol. 26, nº 52, jul/dez 2006.

Persona. Buenos Aires, Ano 1, nº 1, outubro de 1974.

Persona. Buenos Aires, ano 1, nº 3, dezembro de 1974.

PICANÇO, Felícia Silva. Amélia e a mulher de verdade: representações dos papéis da mulher e do homem em relação ao trabalho e à vida familiar. In: ARAÚJO, Clara; SCALON, Celi (orgs). Gênero, família e trabalho no Brasil. Rio de Janeiro: FGV, 2005.

RIBEIRO, Carlos Antonio Costa. Classe e gênero no Brasil contemporâneo: mobilidade social, casamento e divisão do trabalho doméstico. In: ARAÚJO, Clara; SCALON, Celi (orgs). Gênero, família e trabalho no Brasil. Rio de Janeiro: FGV, 2005.

SCOTT, Joan. Gênero: uma categoria útil de análise histórica. Educação e Realidade. Porto Alegre, 16(2). Jul/Dez, 1990.

SILVEIRA, Maria Lucia da. Reflexão coletiva sobre quatro experiências de organização das mulheres na socialização do trabalho de alimentação. In: SILVEIRA, Maria Lucia da; TITO, Neuza (orgs). Trabalho doméstico e de cuidados. Por outro paradigma de sustentabilidade da vida humana. São Paulo: SOF, 2008.

TABAK, F. A dona-de-casa no Brasil. In: DURAN, Maria Angeles. A dona de casa: crítica política da economia doméstica. Rio de Janeiro: Edições Graal, 1983.

TODAS. Buenos Aires, Ano 2, $\mathrm{n}^{\circ}$ 3, 1980.

TORRES, Cristina. El trabajo doméstico y las amas de casa - el rosto invisible de las mujeres. Mujer y Trabajo ${ }^{\circ}$ 2. Montevideo: CIEDUR, 1988. 